ISSN 1981-416X

Licenciado sob uma Licença Creative Commons

\title{
Paulo Freire dialogando com a matemática
}

\author{
Paulo Freire dialoguing with mathematics \\ Paulo Freire dialogando con las matemáticas
}

\section{Kalina Lígia Almeida de Brito Andrade*}

Universidade Federal do Tocantins, Miracema do Tocantins, TO, Brasil

\section{Resumo}

Após algumas reflexões acerca das obras do educador Paulo Freire, observamos o quanto seus ensinamentos e conjecturas, aliados a teorias de outros autores como Carrarer, Lorenzato e Fiorentini, se inserem perfeitamente no quadro de baixa qualidade do desempenho por que passa o processo de ensino e aprendizagem da Matemática. $\mathrm{O}$ autor mostra com propriedade o quanto é possível fazer a diferença em uma sala de aula, transformando esse cenário de mecanicismo, autoritarismo e descontentamento em um ambiente onde prevalece a dinamicidade, a cumplicidade, a tolerância e o estímulo à busca pelo conhecimento, onde deve haver a cooperação e a participação efetiva de todos os envolvidos na aquisição do conhecimento. Observamos a necessidade de os professores (re)significarem seus saberes e práticas e não dependerem exclusivamente de sua formação, mas estarem se aperfeiçoando continuamente e implantando propostas inovadoras, buscando sair de sua zona de conforto, fazendo o aluno compreender e construir suas

* KLABA: Doutorado em Educação, e-mail: kalina@mail.uft.edu.br 
próprias habilidades matemáticas, além de desenvolver uma consciência crítica, auxiliando-os a compreenderem e transformarem o mundo a sua volta. Dessa forma, apresentamos um diálogo entre a Matemática que está sendo exposta hoje aos nossos educandos e as reflexões apresentadas por Paulo Freire e outros autores, visando transformar a condição de ensino bancário em que se encontra esta disciplina em que muitos educadores insistem em laborar em uma prática pedagógica dinâmica, criativa, que estimule aos educandos a construírem seu próprio conhecimento.

Palavras-chave: Matemática. Prática Pedagógica. Diálogo.

\section{Abstract}

After some reflections on the works of the educator Paulo Freire, we observe how much his teachings and conjectures allied to the theories of other authors like Carrarer, Lorenzato and Fiorentini fit perfectly in the frame of low performance quality that passes the process of teaching and learning of the Mathematics. The author shows with propriety how much it is possible to make the difference in a classroom transforming this scenario of mechanicism, authoritarianism and discontent in an environment where dynamicity, complicity, tolerance and the stimulus to the search for knowledge prevail, where there should be cooperation and effective participation of all those involved in the acquisition of knowledge. We note the need for teachers to (re)signify their knowledge and practices and not rely solely on their training, but to continuously improve and implement innovative proposals, seeking to step out of their comfort zone, making the students understand and build their own mathematical skills, as well as develop critical awareness, by helping them to understand and transform the world around them. Thus, we present a dialogue between the Mathematics that is presented today to our students and the reflections presented by Paulo Freire and other authors, aiming at transforming the condition of banking education in which this discipline is found and which many educators insist on working in a dynamic, creative pedagogical practice that encourages learners to build their own knowledge.

Keywords: Mathematics. Pedagogical Practice. Dialogue. 


\section{Resumen}

Después de algunas reflexiones acerca de las obras del educador Paulo Freire, observamos cuánto sus enseñanzas y conjeturas aliados a teorías de otros autores como Carrarer, Lorenzato y Fiorentini se inserta perfectamente en el cuadro de baja calidad del desempeño por el que pasa el proceso de enseñanza y aprendizaje de la enseñanza las matemáticas. El autor muestra con propiedad cuánto es posible hacer la diferencia en un aula transformando ese escenario de mecanicismo, autoritarismo y descontento en un ambiente dinámico donde prevalece la dinamicidad, la complicidad, la tolerancia y el estímulo a la búsqueda del conocimiento, donde debe la cooperación y la participación efectiva de todos los involucrados en la adquisición del conocimiento. Se observa la necesidad de que los profesores (re) signifiquen sus saberes y prácticas y no dependen exclusivamente de su formación, sino que se estén perfeccionando continuamente e implantando propuestas innovadoras, buscando salir de su zona de confort, haciendo al alumno comprender y construir sus propias habilidades matemáticas, además de desarrollar una conciencia crítica ayudándoles a comprender y transformar el mundo a su alrededor. De esta forma, presentamos un diálogo entre las Matemáticas que se está presentando hoy a nuestros educandos y las reflexiones presentadas por Paulo Freire y otros autores, con el objetivo de transformar la condición de enseñanza bancaria en que se encuentra esta disciplina y que muchos educadores insisten en trabajar en una escuela práctica pedagógica dinámica, creativa que estimule a los educandos a construir su propio conocimiento.

Palavras clave: Matemáticas. Práctica pedagógica. Diálogo.

\section{Introdução}

Este trabalho surgiu depois de passarmos algumas semanas revisitando algumas obras de Paulo Freire e nos deleitando com muitas de suas pérolas de ensinamentos. Vimos que nossos diálogos a respeito deste educador não poderiam permanecer fechados entre quatro paredes e depois serem fadados ao esquecimento, mas necessitavam deixar alguma marca, alguma produção que pudesse mostrar como é possível dialogar 
com Paulo Freire perpassando por diversas áreas, tomarmos como nossos os seus ensinamentos e tentarmos fazer a diferença em uma sala de aula - e até mesmo numa sociedade fragilizada como a nossa. E uma dessas áreas, aqui explicitada, será a Matemática. Mais precisamente o processo de ensino e aprendizagem desta disciplina, o qual pode se servir das teorias deste mestre, buscando viabilizar meios para que este processo seja mais significativo para alunos e professores ou, como bem nos ensina Freire, educandos e educadores.

Sabemos que será impossível fazer um passeio por todas as suas obras e até mesmo traçarmos considerações sobre todas as categorias contidas em uma dada obra sua, pois elas são recheadas de fortes lições não só de como ensinar e alfabetizar, mas também, e acima de tudo, lições de humanidade, de fé, de amor, de abnegação, de renúncia, de esperança, de liberdade, de tolerância, de transformação, de aprendizagens, de rupturas possíveis, e, resumindo tudo isso, lições de vida adquiridas por meio das relações com o mundo, com o homem e com o nosso Criador.

Dessa forma, o objetivo deste trabalho é revisitar algumas obras de Paulo Freire, realizando um diálogo entre estas e a realidade educacional na qual está inserida a Matemática de nossas escolas.

\section{Matemática e formação de professores: uma conversa...}

A Educação Matemática surgiu por volta do século XIX como uma preocupação de matemáticos, pesquisadores e professores de Matemática do ensino fundamental até o ensino superior e é, segundo Flemming, Luz e Mello (2005), caracterizada como uma área de atuação que busca, a partir de referenciais teóricos consolidados, análises, soluções e alternativas que inovem o ensino da Matemática.

Apesar de ela ter surgido com este objetivo e existirem estudos e pesquisas tentando sanar os problemas e inovar o ensino da matemática, atualmente ainda encontramos resultados insatisfatórios obtidos na docência nos diversos níveis de ensino, ou seja, desde a educação infantil até a 
universidade. O mais grave destes problemas é a evasão, quando o aluno desiste de seus estudos. E Lorenzato (2010, p. 1), comentando este fato, afirma:

A exclusão escolar, seja por evasão, seja por repetência, é grande, e a Matemática é a maior responsável por isso. O prejuízo educacional que a mais temida das matérias escolares causa não se restringe à escola, pois as pessoas passam a vida fugindo da Matemática e, não raro, sofrendo com crendices ou preconceitos referentes a ela.

O que percebemos é que as aulas de matemática continuam mecânicas, livrescas, descontextualizadas e têm sido caracterizadas por uma grande quantidade de conteúdos sem significação no cotidiano que resultam em baixa qualidade de rendimento dos alunos. Muitas situações-problema têm constituído o ensino de matemática, como metodologias que oferecem poucos resultados positivos e objetivos que não seriam tão significativos para o estudante (GRANDO, 1995, p. 24).

Fiorentini (2008, p. 45), corroborando esse mesmo pensamento, explicita:

Os saberes e os processos de ensinar e aprender, tradicionalmente desenvolvidos pela escola, se tornaram cada vez mais obsoletos e desinteressantes para os alunos. O professor passou, então, a ser continuamente desafiado a atualizar-se e tentar ensinar de um modo diferente daquele vivido em seu processo de escolarização e formação profissional.

Sabemos que o conhecimento está em constante mudança. Daí a necessidade também de o professor estar em uma busca permanente pela formação para que possa acompanhar todo o processo. Essa formação deve lhe possibilitar o acesso a novas informações e lhe fornecer subsídios para pensar em novas metodologias mais adequadas, que lhe permitam lidar com a informação enquanto problema em movimento.

E, segundo os PCNs, a formação de professores é um sério problema a ser enfrentado no ensino no Brasil, pois falta uma formação qualificada, tanto inicial quanto continuada, para que se verifique uma boa prática no exercício da docência. Segundo os PCNs, o investimento na 
formação dos professores, não só inicial como também continuada, é primordial para um bom desenvolvimento do processo educativo. Vejamos:

\begin{abstract}
Além de uma formação inicial consistente, é preciso considerar um investimento educativo contínuo e sistemático para que o professor se desenvolva como profissional de educação. O conteúdo e a metodologia para essa formação precisam ser revistos para que haja possibilidade de melhoria do ensino. A formação não pode ser tratada como um acúmulo de cursos e técnicas, mas sim como um processo reflexivo e crítico sobre a prática educativa. Investir no desenvolvimento profissional dos professores é também intervir em suas reais condições de trabalho (BRASIL, 1998, p. 25).
\end{abstract}

Esses fatores podem favorecer tanto o sucesso como o insucesso do ensino-aprendizagem da disciplina. Nesse sentido, ao recorrer aos PCNs de Matemática (BRASIL, 1998, p. 24), verifica-se que:

Parte dos problemas referentes ao ensino de matemática estão relacionados ao processo de formação do magistério, tanto em relação à formação inicial como à formação continuada. Decorrentes dos problemas da formação de professores, as práticas na sala de aula tomam por base livros didáticos, que, infelizmente, são muitas vezes de qualidade insatisfatória. A implantação de propostas inovadoras, por sua vez, esbarra na falta de uma formação profissional qualificada, na existência de concepções pedagógicas inadequadas e, ainda, nas restrições ligadas às condições de trabalho.

A respeito da formação inicial desse profissional há problemas quando se tem pouca apropriação de informações e noções superficiais sobre essa área do conhecimento humano, pois no curso, em especial de Pedagogia, que habilita para ministrar aulas nas séries iniciais do ensino fundamental, é necessário se ter uma visão ampla das demais disciplinas que atuarão conhecendo as metodologias de ensino, os modelos "ideais" de escola e outros assuntos necessários à compreensão do seu trabalho, como se percebe em pouco tempo de estudos o professor precisa ter domínio sobre todas essas questões para realizar um bom trabalho. 
Outro ponto assinalado pelos $\mathrm{PCN}$ s acima é o livro didático, que muitas das vezes é de qualidade insatisfatória, além de ser uma "muleta" para muitos professores, que sem eles nada podem fazer. Atualmente, porém, contamos com uma política de escolha desse instrumento mediador da aprendizagem realizada pelos próprios professores por meio do Programa Nacional do Livro Didático - PNLD. Mesmo assim, o livro didático, que antes era tido como o porto seguro do professor, hoje se tornou mais um guia ou um norte que auxilia todo o trabalho que permeia o ambiente de sala de aula. Complementando, os pesquisadores Gérard e Roeglers (1998), citados no PNLD de 2013, expõem que, em relação ao professor, o livro didático desempenha, entre outras, as importantes funções de auxiliar no planejamento anual do ensino da área e na gestão das aulas, propiciar a aquisição dos conhecimentos, atuando como texto referência, favorecer a formação didático pedagógica e auxiliar na avaliação da aprendizagem do aluno (BRASIL, 2013).

Estes fatos perpassam outro problema apontado por Freire, que é o descaso com a classe educadora. Ele defende-a de forma taxativa:

Uma das formas de luta contra o desrespeito dos poderes públicos pela educação, de um lado, é a nossa recusa a transformar nossa atividade docente em puro bico, e de outro, a nossa rejeição a entendê-la e a exercê-la como prática efetiva de "tias e de tios". É como profissionais idôneos - na competência que se organiza politicamente está talvez a maior força dos educadores - que eles e elas devem ver-se a si mesmos e a si mesmas. É nesse sentido que os órgãos de classe deveriam priorizar o empenho de formação permanente dos quadros do magistério como tarefa altamente política e repensar a eficácia das greves (FREIRE, 2000, p. 75-76).

Quando não conseguem alcançar essas questões, os educadores recorrem à alternativa oferecida pela escola, a formação continuada, que muitas vezes se resume a estudo e discussões de textos, mas que acaba sendo uma "sobrecarga" para o professor, por ser realizada nos poucos momentos que reserva para o descanso pessoal, ou por trazer um aglomerado de "dicas" de ensino de outras regiões para aplicar em escolas que 
necessitam de um olhar cuidadoso sobre os seus problemas, levando a deixar de lado as diferenças de contextos sociais, culturais, econômicos e políticos da realidade da qual faz parte.

Em contrapartida, quando se propõe a ruptura das metodologias ultrapassadas pelas inovadoras, há resistência por parte do professor, pelo fato de não estar preparado para lidar com o novo ou diferente, pois em todo o seu processo educativo teve contato apenas com a metodologia tradicional, mas também pela falta de incentivos financeiros e de materiais didáticos adequados para melhorar o seu trabalho.

\section{O aqui e o agora dos educandos}

Ensinar matemática é um desafio, pois não dá mais para trabalhar com essa disciplina utilizando apenas a perspectiva tradicional de ensino. É importante levar em consideração o contexto social em que o aluno está inserido, suas experiências anteriores e seus valores culturais, sociais e morais. Sempre que o aluno realiza atividades, principalmente as que exigem concentração, ele leva em consideração suas experiências anteriores, outras situações que possam lhe mostrar uma saída (BRASIL, 1998). Dessa forma, não se deve apresentar a matemática como uma disciplina fechada, abstrata ou desligada da realidade.

O professor deve chegar à sala de aula conhecendo a realidade de seus alunos/educandos, seu cotidiano, suas experiências e trabalhar de forma a inseri-los nas atividades. Fazer com que os alunos vivenciem o conteúdo que tenha a ver com seu contexto cultural, social e não um conteúdo desconexo da realidade, o que é defendido por Freire (1997) comentando sobre o assunto:

É preciso que o(a) educador(a) saiba que o seu "aqui" e o seu "agora" são quase sempre o "lá" do educando. Mesmo que o sonho do(a) educador(a) seja não somente tornar o seu "aqui-agora", o seu saber, acessível ao educando, mas ir mais além de seu "aqui-agora" com ele ou compreender, feliz, que o educando ultrapasse o seu "aqui", para que este sonho 
se realize tem que partir do "aqui" do educando e não do seu. No mínimo, tem de levar em consideração a existência do "aqui" do educando e respeitá-lo. No fundo, ninguém chega lá, partindo de lá, mas de um certo aqui. Isto significa, em última análise, que não é possível ao(a) educador(a) desconhecer, subestimar ou negar os "saberes de experiência feitos" com que os educandos chegam à escola (FREIRE, 1997, p. 31).

E ainda,

[...] Por que não estabelecer uma necessária "intimidade" entre os saberes curriculares fundamentais dos alunos e a experiência social que eles têm como indivíduos? Por que não discutir as implicações políticas e ideológicas de um tal descaso dos dominantes pelas áreas pobres da cidade? A ética de classe embutida neste descaso? Porque, dirá um educador reaccionariamente pragmático, a escola não tem nada a ver com isso. A escola não é partido. Ela tem que ensinar os conteúdos, transferi-los aos alunos. Aprendidos, estes operam por si mesmos (FREIRE, 2000, p. 34).

No caso da Matemática, podemos usar inúmeros exemplos do cotidiano dos alunos como os jogos, atividades e brincadeiras como futebol, baralho, compras no supermercado, construção de uma quadra, de um campinho para jogar bola, venda de geladinhas, dentre outros. Nesse sentido, percebe-se que o universo de atividades se utilizando da realidade é enorme e variado, pois a Matemática se divide em áreas como a aritmética e a geometria que são riquíssimas em exemplos que podem ser extensivamente explorados.

Rosamund Sutherland (2009, p. 43), também expõe a importância da Matemática na vida social e na vida escolar do aluno, relatando que eles trazem experiências de fora da vida escolar:

Os estudantes não apenas trazem suas experiências escolares prévias em matemática para uma nova situação de aprendizagem, mas também trazem suas experiências de fora da escola. Ao longo dos anos escolares, os jovens participam, junto com adultos e outros jovens, de toda uma gama de práticas matemáticas cotidianas relacionadas ao trabalho e ao tempo livre que podem influenciar sua aprendizagem de matemática na 
escola, tais como jogar cartas, ajudar com tarefas gerais em casa, planejar um feriado, trabalhar em uma loja ou trabalhar com um irmão mais velho em sua tarefa de casa.

Embora tenhamos defendido a utilização do cotidiano dos alunos em exemplos e atividades em sala de aula, alertamos para o fato que não teremos exemplos e contextualização para todos os assuntos. Não teremos "receitas" infalíveis para todos os conteúdos matemáticos. É uma questão de atenção no sentido de não deixar as aulas se tornarem mecânicas e enfadonhas, mas de explorar o potencial dos alunos e sua participação efetiva nas reflexões e diálogos provocados no âmbito de sala de aula.

E, fazendo um paralelo desta temática do processo de ensino e aprendizagem com Paulo Freire, vemos que este também evidencia a participação efetiva e crítica do aluno no processo de construção do seu conhecimento salientando: "A visão da liberdade tem nesta pedagogia uma posição de relevo. É a matriz que atribui sentido a uma prática educativa que só pode alcançar efetividade e eficácia na medida da participação livre e crítica dos educandos" (FREIRE, 1967, p. 4).

\section{O aluno e o conhecimento: uma relação de amor}

Analisar e compreender como as crianças aprendem é essencial. Os conhecimentos sobre como as crianças aprendem Matemática vêm de muito tempo atrás, com os estudos de Jean Piaget (1896-1980) e Vygotsky (1896-1934), motivados pelas descobertas da psicologia do desenvolvimento e da abordagem socioconstrutivista, e outros pesquisadores mais recentes como os franceses Guy Brousseau e Gérard Vergnaud, preocupados com a baixa qualidade do desempenho dos estudantes, apresentam algumas propostas para enfrentar as dificuldades encontradas no processo de ensino e aprendizagem da matemática. Aos poucos, aparecem em programas de formação continuada, mostrando maneiras eficientes de ensino da disciplina. 
A importância da matemática no currículo escolar não é novidade, bem como não é novidade seu uso no cotidiano de qualquer pessoa, e isso é retratado pelo papel que deve ser exercido pelo professor no espaço escolar. O professor deve criar condições e um ambiente em que poderá entrelaçar conteúdos escolares e a vida social do aluno, expandindo e ampliando os horizontes de sua vida pessoal e profissional. Afinal, educar não se trata apenas de repassar informações, mas de ajudar a pessoa a construir seu próprio conhecimento, a ter consciência de si mesma e da sociedade em que vive, aceitando-se como pessoa e procurando aceitar os outros. Através da educação a pessoa descobrirá novos caminhos e poderá escolher o que estiver mais próximo da sua visão de mundo.

A relação que deve existir entre o professor e o aluno em uma sala de aula é um passo importante para favorecer o ambiente propício e promissor aos encaminhamentos necessários para uma aprendizagem mais efetiva, também defendida por Alves:

A importância da matemática no currículo escolar é ressaltada por José Carlos G. de Oliveira (1993) no papel a ser desenvolvido pelo professor em sala de aula, papel esse que perpassa pela visão de educador, de estimulador, não esperando apenas que a escola lhe forneça condições propícias, mas, sim, que construa, em todos os momentos da ação pedagógica, diretrizes que ampliem os conhecimentos para além dos muros escolares, sem perder de vista os conteúdos, vendo o sujeito histórico, inserido no mundo, visando sempre seu crescimento (ALVES, 2001, p. 22).

Na concepção de Freire, o diálogo é uma relação horizontal que pode ser estabelecida em qualquer local: consiste num ato de amor, humildade, esperança, fé e confiança. Freire é um dos defensores das relações dialógicas entre os seres humanos em busca de um reencontro consigo mesmo:

O diálogo fenomeniza e historiciza a essencial intersubjetividade humana; ele é relacional e, nele, ninguém tem iniciativa absoluta. Os dialogantes "admiram" um mesmo mundo; afastam-se dele e com ele coincidem: 
nele põem-se e opõem-se. Vimos que, assim, a consciência se existencia e busca perfazer-se. O diálogo não é um produto histórico, é a própria historicização. É ele, pois, o movimento constitutivo da consciência que, abrindo-se para a infinitude, vence intencionalmente as fronteiras da finitude e, incessantemente, busca reencontrar-se além de si mesma. Consciência do mundo, busca-se ela a si mesma num mundo que é comum; porque é comum esse mundo, buscar-se a si mesma é comunicar-se com o outro. $\mathrm{O}$ isolamento não personaliza porque não socializa. Intersubjetivando-se mais, mais densidade subjetiva ganha o sujeito (FREIRE, 1983, p. 8-9).

A aprendizagem ou fracasso dos alunos perante a matemática é resultado das relações e interações demonstradas desde os primeiros dias da vida escolar entre a Matemática e os alunos. Por isso, o papel que o professor exerce é essencial no processo de aprendizagem dessa disciplina, e a sua metodologia de ensino e sua prática são decisivas para o comportamento dos alunos (LORENZATO, 2010, p. 1). Um aspecto importante defendido é a aprendizagem que tem sintonia com o ego, com os desejos, com as intenções e com os gostos das crianças, o que gera alegria e orgulho.

Os professores de Matemática mais que "ministradores de aulas" devem ser mediadores do conhecimento, auxiliadores, fazendo com que os alunos se tornem seres criativos, reflexivos e críticos, interativos, colaboradores, que podem e devem opinar, participar, livres para pensar e construir seu próprio conhecimento como bem expõe Paulo Freire (1967, p. 56), "O que importa, realmente, ao ajudar-se o homem é ajudá-lo a ajudar-se. (E aos povos também.) É fazê-lo agente de sua própria recuperação. É, repitamos, pô-lo numa postura conscientemente crítica diante de seus problemas".

E, ainda

De uma educação que tentasse a passagem da transitividade ingênua à transitividade crítica, somente como poderíamos, ampliando e alargando a capacidade de captar os desafios do tempo, colocar o homem brasileiro em condições de resistir aos poderes da emocionalidade da própria transição. Armá-lo contra a força dos irracionalismos, de que 
era presa fácil, na emersão que fazia em posição transitivante ingênua (FREIRE, 1967, p. 85).

O ser crítico é um ser bastante valorizado por Freire (2000) que explicita a necessidade de o aluno inquietar-se diante do desconhecido e dos desafios que a escola e a vida lhes impõem. Ser curioso, principalmente na Matemática, surge como ponto de partida para novas descobertas, para novas indagações, como forma de não se acomodar, não se aquietar perante as dúvidas e perante a realidade.

A curiosidade como inquietação indagadora, como inclinação ao desvelamento de algo, como pergunta verbalizada ou não, como procura de esclarecimento, como sinal de atenção que sugere e alerta faz parte integrante do fenômeno vital. Não haveria criatividade sem a curiosidade que nos move e que nos põe pacientemente impacientes diante do mundo que não fizemos, acrescentando a ele algo que fazemos (FREIRE, 2000, p. 35).

Neste texto Freire chama a atenção não só do educando, mas também do educador, quando alerta para a necessidade de uma prática pedagógica suscetível a transformações, o educador deve ter sempre uma postura crítica que lhe permita, após identificar os erros, fazer os alunos aprenderem com eles, revendo suas posturas e comportamentos, suas ações e atitudes visando à promoção de mudanças reais que levem à melhoria das condições de vida de cada um na sociedade.

\section{Dizendo não ao ensino "bancário"}

Nessa perspectiva de promoção de mudanças e de transformação, chamamos a atenção para o fato de que na Matemática é muito comum alguns alunos apresentarem dificuldades e muitos logo dizem: "eu não aprendo", "não me entra na cabeça" ou "não dou conta". Vemos que muitas vezes, este fato, depende de uma postura crítica também do educador, que deve criar condições e meios para que esta aprendizagem se efetue e se torne prazerosa. 
A matemática tem sido considerada uma disciplina estanque, uma ciência pronta e acabada e, numa definição mais ousada, uma ciência repleta de certeza e poder e, ainda, destinada a gênios. Analisando o seu ensino, percebe-se que o que prevalece nas salas de aula são ainda os métodos tradicionais de ensino com o incentivo à memorização de fórmulas, regras, intermináveis listas de exercícios, os famosos "arme e efetue", exercícios descontextualizados, com o objetivo de a todo custo vencer conteúdos, programas, concordando com Paulo Freire quando expõe sobre sua concepção bancária.

Macedo, Petty e Passos (2005) comentam que "uma das formas interessantes de promover a aprendizagem ou avaliar é a situação-problema". Dessa forma, faltam situações-problema em que a curiosidade das crianças seja aguçada, ambientes em que a interação, a criatividade, o diálogo e a troca de ideias sejam a tônica, como bem esclarecem Cerquetti-Alberkane e Berdonneau (2011, p. 4) sobre como se trabalhar a Matemática com as crianças:

Lidar com Matemática, é antes de tudo, oferecer à criança a oportunidade de agir, e, posteriormente, levá-la a refletir acerca de suas ações: reviver em pensamento os acontecimentos que acabaram de se desenvolver, antecipar o que poderia vir a acontecer, procurar prever... Desta forma, ela não somente poderá ser confrontada com uma quantidade razoável de fatos com os quais progressivamente se familiarizará (principalmente através de repetidos contatos), como também, e mais do que isso, irá elaborar imagens mentais relativas a eles, e, ao vinculá-los e dar-lhes sentido, estruturar pouco a pouco seus conhecimentos.

No contexto de ressignificação de saberes e práticas de professores de Matemática Cestari (2000, apud ESPINOSA; FIORENTINI, 2005), destaca três princípios que podem auxiliar na construção de ambientes mais dinâmicos e contextos de diálogos importantes em sala de aulas como: incentivar a emergência da dúvida e da curiosidade, visando o estímulo à fala; estar aberto às contribuições dos alunos e valorizar as respostas deles. Espinosa e Fiorentini, portanto, descartam de vez a 
educação bancária (FREIRE, 2000) e defendem a sala de aula como um espaço ativo onde um aprende com o outro, numa troca recíproca de saberes e pensamentos.

E ainda argumenta Freire:

O educador faz "depósitos" de conteúdos que devem ser arquivados pelos educandos. Desta maneira a educação se torna um ato de depositar, em que os educandos são os depositários e o educador o depositante. O educador será tanto melhor educador quanto mais conseguir "depositar" nos educandos. Os educandos, por sua vez, serão tanto melhores educados, quanto mais conseguirem arquivar os depósitos feitos (FREIRE, 1983, p. 66).

Paulo Freire também nos alerta quanto a nossas práticas enquanto docente que não se forma continuamente, que estagna no tempo e no espaço.

O professor que não leve a sério sua formação, que não estude, que não se esforce para estar à altura de sua tarefa não tem força moral para coordenar as atividades de sua classe. Isso não significa, porém, que a opção e a prática democrática do professor ou da professora sejam determinadas por sua competência científica. Há professores e professoras cientificamente preparados mas autoritários a toda prova. O que quero dizer é que a incompetência profissional desqualifica a autoridade do professor (FREIRE, 2000, p. 103).

Dessa forma, o ensino da Matemática deve se voltar para a exploração de metodologias que incentivem a busca de estratégias, o levantamento de hipóteses, de suposições, a argumentação, o trabalho coletivo, a criatividade, a iniciativa pessoal e a autonomia advinda do desenvolvimento da confiança na própria capacidade de conhecer e enfrentar desafios. Neste sentido, a Matemática não é um olhar para as coisas prontas e definitivas, mas a construção e a apropriação de um conhecimento pelo aluno, que se servirá dele para compreender e transformar sua realidade.

Sobre este processo de ensino e aprendizagem, Freire (2000, p. 77) nos esclarece: 
Mulheres e homens somos os únicos seres que, social e historicamente, nos tornamos capazes de aprender. Por isso, somos os únicos em quem aprender é uma aventura criadora, algo, por isso mesmo muito mais rico do que meramente repetir a lição dada. Aprender para nós é construir, reconstruir, constatar para mudar o que não se faz sem abertura ao risco e à aventura do espírito.

Ainda segundo ele próprio, "é pensando criticamente a prática de hoje ou de ontem que se pode melhorar a próxima prática" (FREIRE, 2000, p. 46). Devemos viver num repensar constante sobre nossas práticas pedagógicas, fazendo sempre uma reflexão na ação e sobre a ação visando sempre à melhoria do processo de ensino e aprendizagem.

Vale ressaltar que a ação pedagógica em matemática por meio de atividades individuais e em grupo propicia não apenas a troca de informações, mas cria informações que favorecem valores como a sociabilidade, a cooperação, o respeito mútuo entre os alunos, possibilitando aprendizagens significativas.

Sobre essas relações, principalmente em sala de aula, Freire (1967, p. 42) enfatiza que:

[...] estas não devem ser de acomodação onde o indivíduo apenas recebe o que lhe repassam e se acomoda, mesmo sem ter aprendido, mas deve ser de integração, onde há a cooperação e a participação efetiva na aquisição de seu próprio conhecimento. Portanto, enquanto o animal é essencialmente um ser da acomodação e do ajustamento, o homem o é da integração. A sua grande luta vem sendo, através dos tempos, a de superar os fatores que o fazem acomodado ou ajustado.

O professor não é o detentor do saber e os alunos não são depósitos para dentro dos quais este "empurra conteúdos" ou lhes impõe o conhecimento. Esse é o educador bancário citado por Paulo Freire (2000), que em sua obra Pedagogia da Autonomia explicita que, por meio do diálogo, educando e educador podem se entender e buscar alternativas visando sempre o desenvolvimento de um processo de ensino e aprendizagem significativo para ambos. E defende que a relação dialógica é fundamentada 
na cumplicidade entre educador e educando e entre os educandos em suas relações do dia a dia escolar:

Como professor não devo poupar oportunidade para testemunhar aos alunos a segurança com que me comporto ao discutir um tema, ao analisar um fato, ao expor minha posição em face de uma decisão governamental. Minha segurança não repousa na falsa suposição de que sei tudo, de que sou o "maior". Minha segurança se funda na convicção de que sei algo e de que ignoro algo que se junta a certeza de que posso saber melhor o que já sei e conhecer o que ainda não sei. Minha segurança se alicerça no saber confirmado pela própria existência de que, se minha inconclusão, de que sou consciente, atesta, de um lado, minha ignorância, me abre, de outro, o caminho para conhecer (FREIRE, 2000, p. 152-153).

Esta relação deve ser de compartilhamento, de trocas, de busca pela compreensão a partir da integração entre professor e aluno, ou educador-educando como nos esclarece ainda Paulo Freire:

Para o educador-educando, dialógico, problematizador, o conteúdo programático da educação não é uma doação ou imposição - um conjunto de informes a ser depositado nos educandos, mas a revolução organizada, sistematizada e acrescentada ao povo, daqueles elementos que este lhe entregou de forma desestruturada (FREIRE, 1997, p. 47).

Ou seja, o professor deve ouvir o que o aluno tem a dizer, deve escutá-lo em suas angústias, em suas opiniões, haja vista que o professor enquanto ensina, também aprende. Ou seja, existe uma troca, uma via de mão dupla, onde vários saberes são e devem estar circulando em um processo mútuo de elaboração dos conhecimentos envolvidos. Nesse contexto, Paulo Freire critica esse tipo de ensino:

É isso que nos leva, de um lado, à crítica e a recusa ao ensino "bancário", de outro, a compreender que, apesar dele, o educando a ele submetido não está fadado a fenecer; em que pese o ensino "bancário", que deforma a necessária criatividade do educando e do educador, o 
educando a ele sujeitado pode, não por causa do conteúdo cujo "conhecimento" lhe foi transferido, mas por causa do processo mesmo de aprender, dar, como se diz na linguagem popular, a volta por cima e superar o autoritarismo e o erro epistemológico do "bancarismo" (FREIRE, 2000, p. 27).

Assim, necessitamos de professores dinâmicos e criativos que problematizem a Matemática e não professores que só depositem conteúdos nos educandos, fazendo desta disciplina o "bicho-papão" da educação. E é por meio da "problematização" da realidade, da significação de que é possível desenvolver uma concepção libertadora na relação entre professor e aluno e conhecimento e aprendizagem.

Existem vários conteúdos que se poderia tomar como exemplo de estudo da matemática na perspectiva de Paulo Freire. Um deles seria o estudo da geometria e mais precisamente da casa de abelhas como um exemplo de etnomatemática que pode buscar forte subsídio no denominado método Paulo Freire. Poderíamos partir de várias premissas básicas, mas uma delas seria partir da realidade das crianças e fazer o casamento entre o significado matemático e o método freiriano, alfabetizá-las matematicamente sobre as formas geométricas, áreas, medidas, dentre outros - no exemplo citado - e levá-las ao entendimento dessa realidade, desenvolvendo nelas a consciência crítica e viabilizando ferramentas que as auxiliem a compreender e transformar o mundo que as rodeia.

\section{Considerações finais}

Podemos arrematar explicitando que nos atuais processos de ensino e aprendizagem da Matemática as atividades aplicadas em sala de aula não favorecem aos alunos uma visão mais aprofundada desta disciplina, ou seja, as atividades têm sido desenvolvidas com a utilização do raciocínio, mas percebe-se que estas seguem um plano que não visa à individualidade dos alunos. Analisando diversos exemplos da Matemática, percebe-se que o aluno convive com seus conhecimentos tanto fora como 
dentro da escola, e a diferença está no fato de uma ser simples de compreensão por ser aprendida espontaneamente; já a outra precisa de uma pessoa específica para ensiná-la, é cheia de teorias complicadas e muitas vezes os alunos são obrigados a aprendê-la (CARRAHER; CARRARER; SCHLIEMANN, 2010).

O que se observa é que neste processo as aulas continuam tradicionais e sem muito significado para os alunos. São apresentadas metodologias que não oferecem resultados satisfatórios, prevalecendo uma ênfase na grande quantidade de conteúdos sem conexão com o dia a dia, o que resulta em baixa qualidade de rendimento dos alunos.

Nesses casos, percebe-se ainda que, além da relevância da formação inicial, é preciso considerar também a formação continuada e sistemática para que o professor se desenvolva como um profissional de educação transformador de sua realidade, devendo assim, buscar um aperfeiçoamento tanto em conteúdo quanto em metodologia, para que, dessa forma, vislumbremos uma possibilidade de melhoria do ensino.

Dessa forma, em condições de verdadeira aprendizagem, os alunos devem participar da construção e da reconstrução do saber matemático que lhe é ensinado, juntamente com o educador, que se torna igualmente sujeito do processo, utilizando-se do "aqui e agora" dos alunos, explorando situações-problema que tenham significação na vida deles e que eles possam fazer uso destes saberes em suas vivências diárias.

A Figura 1, em anexo, retrata de forma eficiente, baseada nos conceitos e teorias de Paulo Freire, como seria um professor de Matemática em seu papel de incentivador e motivador da aprendizagem desta disciplina, provocando uma educação problematizadora, assumindo que todos somos seres em construção, prontos a mudar sempre que necessário, buscando uma transformação significativa de nosso ser.

Vislumbramos, então, como é rico de experiências e conhecimentos o espaço que é frequentado pelos alunos e que pode ser efetivamente compartilhado. Os diálogos e as aprendizagens podem ocorrer em vários ambientes, sendo essencial valorizar esses contextos para que os 
alunos sejam estimulados a buscar conhecer melhor essa disciplina e estabelecer uma relação sólida entre esses saberes.

\section{Referências}

ALVES, E. M. S. A ludicidade e o ensino de matemática: uma prática possível. Campinas: Papirus, 2001. (Coleção Papirus Educação).

BRASIL. Secretaria de Educação Fundamental. Parâmetros curriculares nacionais: matemática. Brasília: MEC/SEF, 1998.

BRASIL. Guia de livros didáticos: PNLD: Alfabetização matemática e Matemática. Brasília: Ministério da Educação, Secretaria de Educação Básica, 2013. 256 p.

CARRARER, T.; CARRARER, D.; SCHLIEMANN, A. Na vida dez, na escola zero. 15. ed. São Paulo: Cortez, 2010.

CERQUETTI-ALBERKANE, F.; BERDONNEAU, K. O ensino da matemática na educação infantil. Trad. Eunice Gruman. Porto Alegre: Artmed, 2011.

ESPINOSA, A. J; FIORENTINI, D. (Re)significação e reciprocidade de saberes e práticas no encontro de professores de matemática da escola e da universidade. In: FIORENTINI, D.; NACARATO, A. M. (Org.). Cultura, formação e desenvolvimento profissional de professores que ensinam matemática: investigando e teorizando a partir de prática. São Paulo: Musa Editora; Campinas: GEPFPM- PRAPEMFE/UNICAMP, 2005.

FIORENTINI, D. A pesquisa e as práticas de formação de professores de Matemática em face das políticas públicas no Brasil. Bolema, Rio Claro, ano 21, n. 29, p. 43-70, 2008.

FLEMMING, D. M.; LUZ, E. F.; MELLO, A. C. C. Tendências em Educação Matemática. 2. ed. Palhoça: UNISUL Virtual, 2005.

FREIRE, P. Educação como prática da liberdade. Rio de Janeiro: Paz e Terra, 1967. 
FREIRE, P. Pedagogia da autonomia: saberes necessários à prática educativa. 16 . ed. Rio de Janeiro: Paz e Terra, 2000.

FREIRE, P. Pedagogia da esperança: um encontro com a pedagogia do oprimido. Rio de Janeiro: Paz e Terra, 1997.

FREIRE, P. Pedagogia do oprimido. 2. ed. Rio de Janeiro: Paz e Terra, 1983.

GRANDO, R. C. O jogo e suas possibilidades metodológicas no processo ensino aprendizagem da matemática. 1995. 175 f. Dissertação (Mestrado em Educação) Universidade Estadual de Campinas, Faculdade de Educação, Campinas, 1995.

LORENZATO, S. O laboratório de ensino de matemática na formação de professores. Campinas: Autores Associados, 2010. (Coleção Formação de Professores).

MACEDO, L. de; PETTY, A. L. S.; PASSOS, N. C. Os jogos e o lúdico na aprendizagem escolar. Porto Alegre: Artmed, 2005.

SUTHERLAND, R. Ensino eficaz de matemática. Porto Alegre: Artmed, 2009.

Recebido: 06/09/2017

Received: 09/06/2017

Recibido: 06/09/2017

Aprovado: 04/12/2017

Approved: $12 / 04 / 2017$

Aprobado: 04/12/2017 


\section{Anexo}

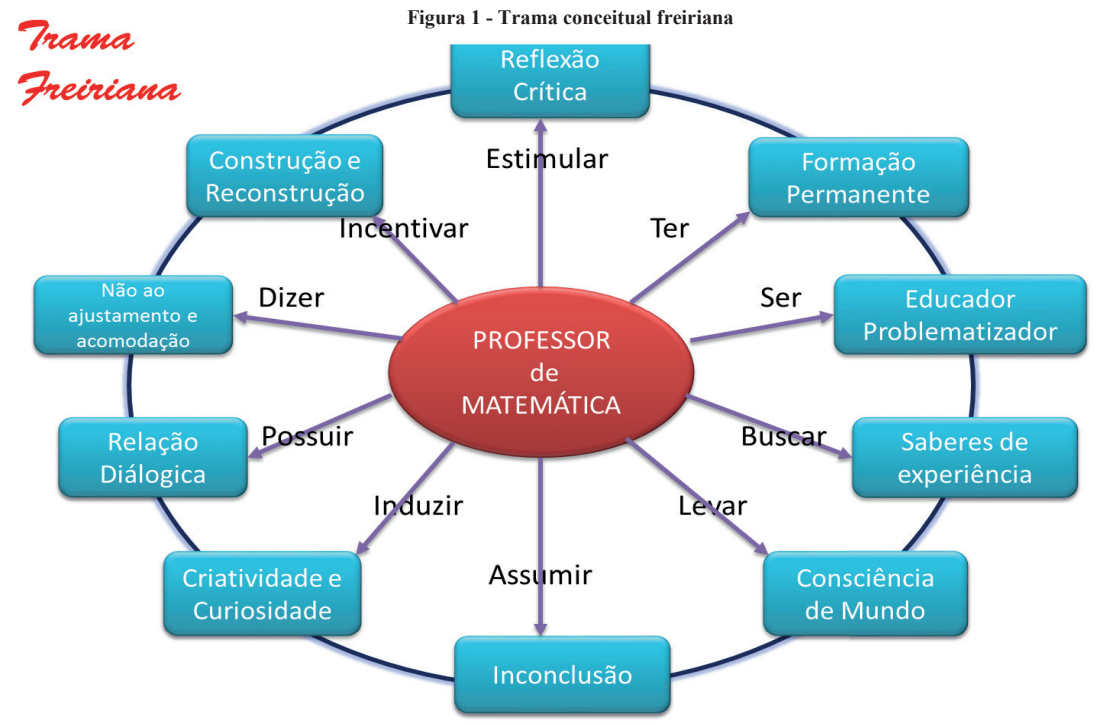

